\title{
Clinical outcomes of 130 patients with primary and secondary lung tumors treated with Cyberknife robotic stereotactic body radiotherapy
}

\author{
Zsolt Levente Janvary¹, Nicolas Jansen², Veronique Baart², Magali Devillers², David \\ Dechambre $^{2}$, Eric Lenaerts², Laurence Seidel ${ }^{3}$, Nicole Barthelemy², Patrick Berkovic², \\ Akos Gulyban², Ferenc Lakosi², Zsolt Horvath¹, Philippe A. Coucke² \\ ${ }^{1}$ Division of Radiotherapy, Department of Clinical Oncology, Faculty of Medicine, University of Debrecen, Debrecen, \\ Hungary \\ 2 Department of Radiation Oncology, Liege University Hospital, Liege, Belgium \\ ${ }^{3}$ Department of Biostatistics, Liege University Hospital, Liege, Belgium
}

Radiol Oncol 2017; 51(2): 178-186.

Received 15 December 2016

Accepted 27 February 2017

\begin{abstract}
Correspondence to: Zsolt Levente Janvary, M.D., Division of Radiotherapy, Department of Clinical Oncology, Faculty of Medicine, University of Debrecen, Nagyerdei krt. 98, 4032 Debrecen, Hungary. Phone: +36 2050620 52; Fax: +36 52255 585; E-mail: janvary.levente@med.unideb.hu, janvarylevente@yahoo.com
\end{abstract}

Disclosure: No potential conflicts of interest were disclosed.

Background. Authors report clinical outcomes of patients treated with robotic stereotactic body radiotherapy (SBRT) for primary, recurrent and metastatic lung lesions.

Patients and methods. 130 patients with 160 lesions were treated with Cyberknife SBRT, including T1-3 primary lung cancers $(54 \%)$, recurrent tumors $(22 \%)$ and pulmonary metastases $(24 \%)$. The mean biologically equivalent dose (BED ${ }_{10 G y)}$ was 151 Gy (72-180 Gy). Median prescribed dose for peripheral and central lesions was 3x20 Gy and 3x15 Gy, respectively. Local control (LC), overall survival (OS), and cause-specific survival (CSS) rates, early and late toxicities are reported. Statistical analysis was performed to identify factors influencing local tumor control.

Results. Median follow-up time was 21 months. In univariate analysis, higher dose was associated with better LC and a cut-off value was detected at $\mathrm{BED}_{10 \mathrm{G}} \leq 112.5 \mathrm{~Gy}$, resulting in 1-, 2-, and 3-year actuarial LC rates of $93 \%$, vs $73 \%$, $80 \%$ vs $61 \%$, and $63 \%$ vs $54 \%$, for the high and low dose groups, respectively ( $p=0.0061, H R=0.384$ ). In multivariate analysis, metastatic origin, histological confirmation and larger Planning Target Volume (PTV) were associated with higher risk of local failure. Actuarial OS and CSS rates at 1, 2, and 3 years were $85 \%, 74 \%$ and $62 \%$, and $93 \%, 89 \%$ and $80 \%$, respectively. Acute and late toxicities $\geq$ Gr 3 were observed in $3(2 \%)$ and 6 patients (5\%), respectively.

Conclusions. Our favorable LC and survival rates after robotic SBRT, with low rates of severe toxicities, are coherent with the literature data in this mixed, non-selected study population.

Key words: Cyberknife; stereotactic body radiotherapy; non-small cell lung cancer; lung metastasis

\section{Introduction}

Although surgical resection is considered as the standard of care in patients with early-stage nonsmall cell lung cancer (NSCLC), a significant percentage of mostly elderly patients are not eligible for this treatment. Stereotactic body radiotherapy (SBRT) is considered to be an effective and well tolerated, non-invasive treatment option for this population..$^{1,2}$ Efforts have already been made to directly compare the effectiveness and toxicity of SBRT to surgery for operable patients in rand- 
omized trials, but unfortunately, these trials did not reach their accrual target and were prematurily closed because of low recruitment. ${ }^{2}$

However data from prospective trials show consistenly high levels of local control rates with stereotactic irradiation of early stage NSCLC. . $^{3-6}$ Although SBRT literature is more extensive for early stage primary lung cancer, publications concerning recurrent lung tumors and lung metastases also show high local control rates. ${ }^{7-9}$ On the basis of the published clinical experience stereotactic radiotherapy of the lung became one of the most established indications of SBRT. ${ }^{10-11}$ A clear dose-effect relationship has been shown by several SBRT studies, and a $\mathrm{BED}_{10 \mathrm{~Gy}} \geq 100$ Gy (Biologically Effective Dose with an $\alpha / \beta$ of $10 \mathrm{~Gy}$ ) was found to be associated with better results. ${ }^{12}$ Nevertheless, the delivered dose and fraction number should be tailored to the anatomical situation and size of the lesion, as the proximity of critical organs can lead to higher probability of toxicity.

Although there have been attemps for single fraction treatments ${ }^{13-14}$, generally lung SBRT is delivered in 3 to 8 fractions. Treatment-related severe toxicities are uncommon using "risk-adapted" fractionation schemes with lower dose per fraction for central tumors. ${ }^{15}$

The purpose of this study is to evaluate and report the clinical outcomes of the first 130 consecutively treated patients presented with primary, recurrent primary or secondary lung tumors. The primary objective was to analyse local therapeutic efficacy of robotic SBRT and factors influencing local control. The secondary objectives were to evaluate early and late toxicities and survival results.

\section{Patients and methods}

\section{Patients}

Cyberknife $^{\circledR}$ (Accuray Inc. Sunnyvale, USA) robotic SBRT treatments were started at the Liege University Hospital in April 2010. Ordinary indications for SBRT treatment include T1-T2 primary NSCLC, recurrent primary lung tumors, and solitary-, or oligometastases. However, more rarely this treatment is appied on T3 tumors or soliter lymph node metastases. ${ }^{16-19}$ The majority of primary and recurrent lung tumors in our cohort were considered ineligible for surgical resection because of poor lung functions or severe comorbidities. For metastatic lesions medical inoperability; > 1 lesions in different lobes or lungs; prior lobectomy and patient preference were the major causes leading to the choice of SBRT. Based on individual medical consideration and absence of realistic therapeutic alternatives a small number of unusual indications were also included, like patients harboring T3N0 or T1N1 disease. In the present study 130 consecutive patients treated with $\mathrm{BED}_{10 \mathrm{~Gy}} \geq 72$ Gy were evaluated. Central or large tumors were not excluded, but the dose and number of fractions were adapted. Central lesions were defined as lesions located whithin $2 \mathrm{~cm}$ from the pulmonary hilum, heart, great vessels, or trachea. Indications for each individual patient were discussed and approved in multi-disciplinary tumor boards. Especially for primary tumors, pathological confirmation was requested either by bronchofiberoscopy or transthoracic biopsy. For patients considered not eligible for histological confirmation (due to technical or medical reasons), the indication was based on strong clinical suspicion supported by positron emission tomography (PET).

One hundred and thirty patients, with a total of 160 lung lesions were treated between April 2010 and June 2012. Patient and tumor characteristics are listed in Table 1.

TABLE 1. Patient, tumor and treatment characteristcs

\begin{tabular}{|c|c|}
\hline Characteristic & n (\%) \\
\hline Total number of patients/lesions & $130(100 \%) / 160$ (100\%) \\
\hline Mean age in years & 71 (range: 40-92) \\
\hline Male/female ratio & 77 (59\%) / 53 (41\%) \\
\hline No. with COPD & $45(35 \%)$ \\
\hline Mean FEV 1 (\%) & 65 (range: 24-139) \\
\hline Mean FEV 1 (L) & 2 (range: 0.53-3.65) \\
\hline Histological confirmation & $79(61 \%)$ \\
\hline Primary cancer patients/lesions & $81(62 \%) / 86(54 \%)$ \\
\hline TINO & 53 \\
\hline $\mathrm{T} 2 \mathrm{NO}$ & 19 \\
\hline T3NO & 5 \\
\hline $\mathrm{TIN} 1$ & 4 \\
\hline Recurrent tumor patients /lesions (n) & 23 (18\%) / 35 (22\%) \\
\hline Lung metastasis patients /lesions (n) & $26(20 \%) / 39$ (24\%) \\
\hline Mean GTV volume (ml) & 11.5 (range: 0.6-86.5) \\
\hline Mean PTV volume (ml) & 33.2 (range: $5.8-118.1$ ) \\
\hline Location of lesions: peripheral/central & $113(71 \%) / 47$ (29\%) \\
\hline Mean total dose (Gy)/Mean no. of fractions & $60 / 3 \mathrm{fx}$ (range: $40-60 / 3-5 \mathrm{fx}$ ) \\
\hline Mean/median BED ${ }_{10 G y}(G y)$ & $151 / 180 \mathrm{~Gy}$ \\
\hline
\end{tabular}

$\mathrm{BED}=$ mean biologically equivalent dose; $\mathrm{COPD}=$ chronic obstructive pulmonary disease; $\mathrm{FEV} 1=$ forced expiratory volume in 1 second; $\mathrm{fx}$ = fractions; GTV = gross tumour volume; PTV = planning target volume 
Median age of patients at treatment was 71 years (range 40-93), and 59\% $(n=77)$ were males. Distribution of lesions were: $53 \%(n=86)$ primary, $22 \%(n=35)$ recurrent tumor/intrapulmonary metastasis of a lung tumor and $25 \%(n=39)$ metastases from other cancer. Cancer of origin for metastatatic lesions were: colorectal $(49 \% ; n=19)$, salivary gland $(13 \% ; n=5)$, breast $(10 \% ; n=4)$, melanoma $(5 \% ; n=2)$, kidney $(5 \% ; n=2)$, neuroendocrin $(3 \%$; $\mathrm{n}=1)$, multiple primary $(13 \% ; \mathrm{n}=5)$, unkown $(2 \% ; n=1)$. Distribution of histological types for the patient group with pathologically confirmed primary lung cancer was: $47 \%$ adenocarcinoma $(\mathrm{n}=29), 33 \%$ squamosus cell carcinoma ( $\mathrm{n}=21)$, $15 \%$ NSCLC $(n=9), 5 \%$ undifferentiated $(n=3)$. The maximal number of lesions treated by SBRT in the same patient was four. Four patients were presented with stage T1N1 disease. For these patients the affected lymph node(s) were also treated with SBRT. Positivity of these lymph nodes were based on high SUVmax value on PET CT, without cytological confirmation, but usually the histology of the belonging primary tumors were known.

One patient was categorized as T3 for tumor size, the other four T3 patients had mediastinal pleura invasion or separate nodule in the same lobe.

Distribution of the 113 peripheral lesions was : $\mathrm{n}=66$ primary, $\mathrm{n}=21$ recurrent, $\mathrm{n}=26$ metastasis. The group of 47 central lesions was composed of 17 primary tumors plus 3 synchronous N1 lymph nodes, 14 recurrent cancers and 13 metastases.

\section{Treatment preparation}

Technical characteristics and tracking options of the Cyberknife robotic SBRT system have been exhaustively detailed elsewhere. ${ }^{16-17}$ For thoracic tumors there are three different tracking types, which can be appropriately selected according to each clinical case. Synchrony ${ }^{\circledR}$ is a real-time tumor tracking algorithm which requires fiducial markers to be previously inserted inside or near to the target. The fiducials are detected by orthogonal $X$-rays at the treatment room. The system includes an infrared camera that monitors the movement of the chest. During treatment, spatial information on the location of the fiducials and data of the respiratory cycle are connected to redirect the robot, and realize real-time tracking. Fiducial insertion can be contraindicated for some patients because of the inherent risk of pneumothorax. For selected cases, when tumor silhouette is sharply identified on both ortogonal X-ray detector panels, the algorithm of
Xsight Lung ${ }^{\circledR}$ can be used for tracking the target, without the need for implanted markers. When none of these two previously mentioned tracking algorithm is feasible, tracking is performed on the vertebra (XsightSpine ${ }^{\circledR}$ ).

Planning CT images were obtained with a slice thickness of $1 \mathrm{~mm}$. Patients were immobilised using an individual vacuum bag "in supine position, with arms next to the body. Four-dimensional (4D) CT simulation was not introduced for Cyberknife treatment, thus expiration and moderate inspiration CT scans were acquired to estimate magnitude of respiratory releated tumor movement. In case of fiducial-, or direct tumor tracking, only expiration CTs were used for delineation. For patients with fiducial markers, CT simulation was delayed with a minimum of 10 days after implantation to minimise uncertainity linked to the potential marker migration.

The vast majority of patients $(n=125 ; 96 \%)$ had PET CT scans in treatment position using the same individual vacuum bag used at the CT simulation, to optimize target volume definition.

For patients with real-time tumor tracking generally a margin of $3 \mathrm{~mm}$ was applied around the gross tumor volume (GTV) to achieve clinical target volume (CTV). CTV contours were then, corrected manually when overlapping with ribs or mediastinal structures. An additional $2 \mathrm{~mm}$ was added to create planning target volume (PTV).

When real time tumor tracking was not feasible, we used an internal target volume of GTV, large enough to cover all possible tumor positions during the respiratory cycle. After that, the method and the margins for creating CTV-internal target volume (ITV) and PTV was similar to real time tracked patients.

\section{SBRT procedure}

Treatment plans were implemented with Multiplan treatment planning system (TPS) version 5.1 (Accuray Inc. Sunnyvale, USA), using Ray Tracing calculation algorythm. Prescription doses varied between 40 to 60 Gy in 3 to 5 fractions, depending on proximity to organs at risk (OAR) and on tumor size. Dose was typically prescribed to the $80 \%$ isodose line (75-82\%) encompassing the PTV. Dose constrains to OARs were applied according to a class solution (Table 2) which was based on published data of Timmerman and AAPM Taskgroup 101 guidelines. ${ }^{18-19}$

SBRT treatments were performed by Cyberknife Robotic Radiosurgery treatment unit (Accuray Inc. 
Sunnyvale, USA). Treatment consisted of typically 100-200 non-coplanar beams using Iris $^{\circledR}$ various aperture collimator in a range between 15 to $60 \mathrm{~mm}$ with a dose rate of $600 \mathrm{MU} / \mathrm{min}$.

\section{Follow up and toxicity evaluation}

Patients were followed up by the treating radiation oncologist and/or by referring pulmonologist or oncologist. In addition to regular CT-scans, metabolic follow up of treatment effect by PET CT was performed in 118 patients (91\%) to make distinction between local disease progression and localized pulmonary fibrosis. ${ }^{20,21}$ Acute and late toxicities were evaluated using the Common Terminology Criteria for Adverse Events (CTCAE v4.0). Toxicity was classified as acute up to 3 months after SBRT.

The patient follow up time was defined as the period between the first day of Cyberknife treatment to the date of last visit or death.

\section{Statistical analysis}

Patient and lesion characteristics and toxicities were described in terms of means or medians (range) or in terms of numbers (\%). A descriptive analysis was used to present patient and treatment characteristics and toxicity data. Local control (LC), overall survival (OS) and cause-specific survival (CSS) rates were estimated by the Kaplan-Meier method. The prognostic value of patient and tumor characteristics on LC was determined using uni- and multivariate Cox regression models. Results were considered to be statisticallysignificant at $p$-values $\leq 0.05$. Statistical analysis was performed with the SAS version 9.3 software (SAS Institute, Cary, NC, USA).

\section{Ethical considerations}

This retrospective cohort study was approved by institutional review board.

\section{Results}

The mean and median follow up time (FUP) was 21 months (range 2-39) with only 8 cases $(6.2 \%)$ with a follow-up of less than 6 months. Total dose and number of fractions was determined with consideration of tumor location and size. In some cases the initially planned dose was reduced and/or the fraction number was increased in order to better meet OAR constraints. The applied dose and fractionation schemes are described in Table 3.
TABLE 2. Dose constraints for organs at risk

\begin{tabular}{|c|c|c|c|}
\hline Organ & $\begin{array}{l}\text { Type of } \\
\text { constraint }\end{array}$ & $\begin{array}{l}\text { Dose (Gy) for } \\
3 \text { fractions SBRT }\end{array}$ & $\begin{array}{l}\text { Dose (Gy) for } \\
5 \text { fractions SBRT }\end{array}$ \\
\hline Spinal cord & $\mathrm{D}_{\max }$ & 22 (7.33 Gy/fx) & 30 (6 Gy/fx) \\
\hline Esophagus & $\mathrm{D}_{\max }$ & 27 (9 Gy/fx) & 35 (7 Gy/fx) \\
\hline $\begin{array}{l}\text { Trachea and main } \\
\text { bronchi }\end{array}$ & $D_{\max }$ & 30 (10 Gy/fx) & 32 (6.4 Gy/fx) \\
\hline Heart & $\mathrm{D}_{\max }$ & 30 (10 Gy/fx) & 38 (7.6 Gy/fx) \\
\hline Plexus brachialis & $\mathrm{D}_{\max }$ & $24(8 \mathrm{~Gy} / f x)$ & 32 (6.4 Gy/fx) \\
\hline Ribs & $D_{\max }$ & $37(12.3 / f x)$ & $43(8.6 / f x)$ \\
\hline Skin & $\mathrm{D}_{\max }$ & $32(10.6 / f x)$ & $24(4.8 / f x)$ \\
\hline Lung (both lungs) & Volumetric & $\begin{array}{l}\bigvee_{10.5 G \mathrm{Y}}<1500 \mathrm{cC} \\
\bigvee_{11.4 \mathrm{~Gy}}<1000 \mathrm{cC}\end{array}$ & $\begin{array}{l}V_{12.5 G \mathrm{y}}<1500 \mathrm{cC} \\
\mathrm{V}_{13.5 \mathrm{~Gy}}<1000 \mathrm{cC}\end{array}$ \\
\hline Liver & Volumetric & $V_{17.1 G y}<700 \mathrm{cc}$ & $V_{21 G y}<700 \mathrm{cc}$ \\
\hline
\end{tabular}

Delivered dose varied from $\mathrm{BED}_{10 \mathrm{~Gy}}=72 \mathrm{~Gy}(40$ Gy in 5 fractions) to $\mathrm{BED}_{10 \mathrm{~Gy}}=180 \mathrm{~Gy}$ ( $60 \mathrm{~Gy}$ in 3 fractions). The median dose for peripheral lesions was 3x 20Gy, whereas for central lesions the median was 3x 15Gy. Mean/median $\mathrm{BED}_{10 \mathrm{~Gy}}$ for peripheral and central lesions were 170/180Gy and 102/112.5 Gy, respectively. Real-time tumor tracking was performed in $42 \%$ of treatments $(n=66)$ either using gold fiducial based (Synchrony) or direct fluoroscopic (Xsight Lung) methods.

\section{Local control}

For the whole cohort the actuarial 1-, 2-, and 3-year LC rates were $86 \%, 75 \%$, and $62 \%$, respectively.

In univariate Cox regression model, a higher $\mathrm{BED}_{10 \mathrm{~Gy}}$ was associated with better LC $(\mathrm{p}=0.008)$. Analysis of the different dose levels found a cutoff value between BED 112.5 Gy and 132 Gy. Treatments using doses higher than 112.5 Gy

TABLE 3. Dose-fractionation schemes

\begin{tabular}{lll}
\hline $\begin{array}{l}\text { Radiotherapy } \\
\text { scheme }\end{array}$ & BED $_{10 \mathrm{~Gy}}$ (Gy) & $\mathbf{n}(\%)$ \\
\hline $3 \times 20$ Gy & 180 & $96(60 \%)$ \\
$3 \times 18$ Gy & 151.2 & $7(4 \%)$ \\
$3 \times 17$ Gy & 137.7 & $4(2.5 \%)$ \\
$5 \times 12$ Gy & 132 & $1(0,6 \%)$ \\
$3 \times 15$ Gy & 112.5 & $24(15 \%)$ \\
$5 \times 10$ Gy & 100 & $4(2.5 \%)$ \\
$5 \times 9$ Gy & 85.5 & $11(7 \%)$ \\
$5 \times 8$ Gy & 72 & $13(8 \%)$ \\
\hline
\end{tabular}

$\mathrm{BED}=$ mean biologically equivalent dose 


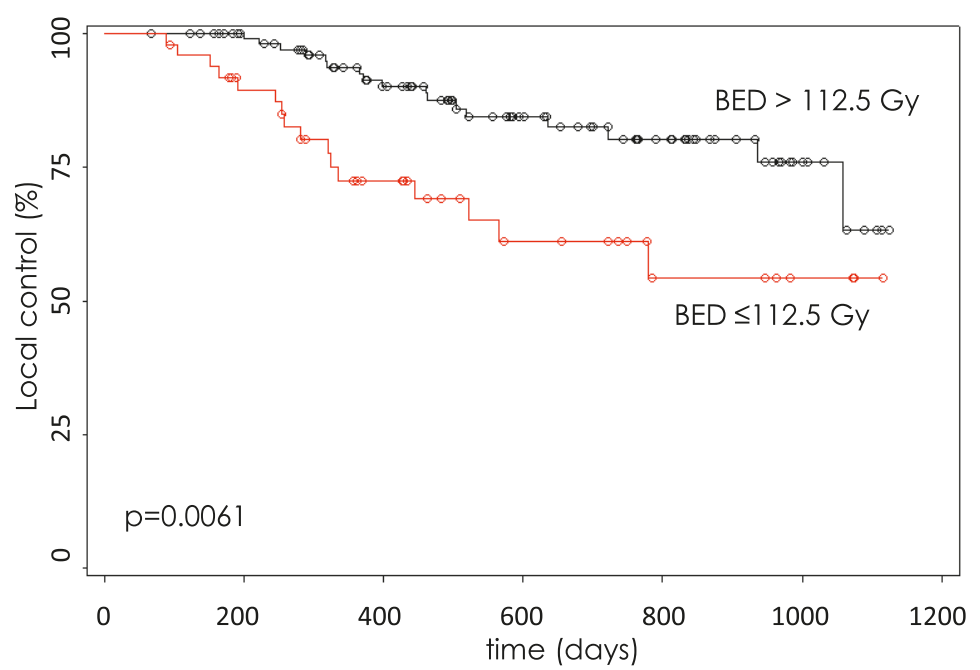

FIGURE 1. Probabilty of local control according to dose (BED $\leq 112.5$ Gy vs. higher).

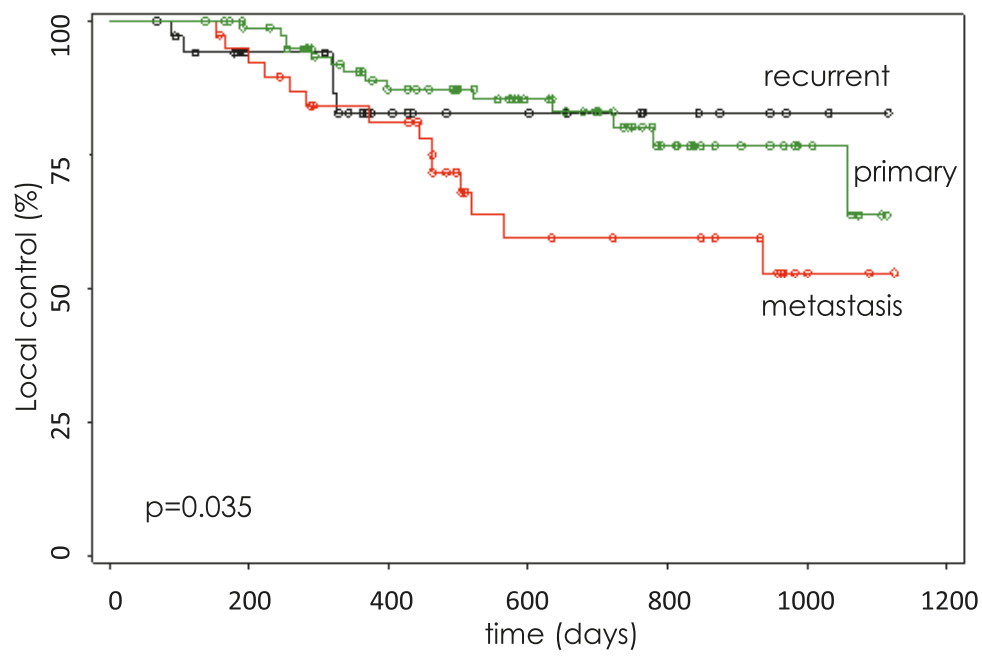

FIGURE 2. Probability of local control for primary $(n=86)$, recurrent $(n=35)$ and metastatic $(n=39)$ lesions.

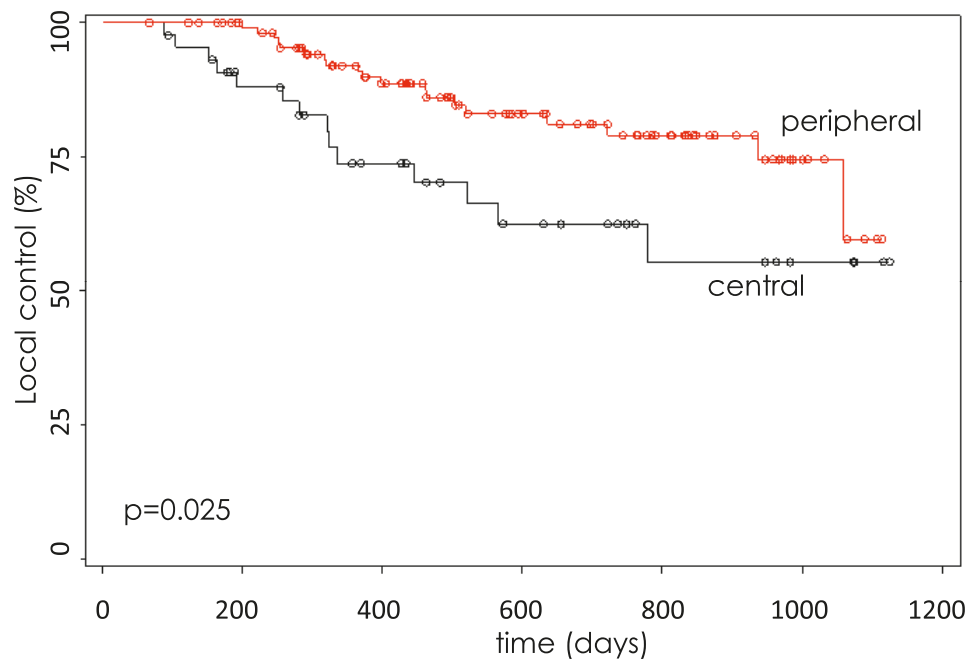

FIGURE 3. Probability of local control for peripheral $(n=113)$ and central $(n=47)$ lesions. showed a significant advantage in terms of LC, resulting 1-, 2-, and 3-year actuarial LC rates of 93\% vs $73 \%, 80 \%$ vs $61 \%$, and $63 \%$ vs $54 \%$, respectively $(\mathrm{p}=0.0061, \mathrm{HR}=0.384$; Figure 1$)$.

In univariate analysis there were no significant differences between primary $(\mathrm{P})$, recurrent $(\mathrm{R})$ and metastatic $(\mathrm{M})$ lesions in terms of actuarial LC ( $\mathrm{p}=$ 0.091). However in pairwise comparison primary tumors provided improved results compared to metastases: 1-, 2-, and 3-year LC rates were $89 \%$ vs $84 \%, 80 \%$ vs $59 \%$, and $64 \%$ vs $53 \%$, respectively ( $\mathrm{p}=$ 0.035; Figure 2). Other factors such as tumor tracking (inclusive tracking modality), and histological confirmation of malignancy had no significant effect on LC.

During separate analysis of the primary tumor group there was no significant difference in LC according to T-stage. However, there was a nonsignificant trend favoring LC in T1 compared to T2 $(\mathrm{p}=0.063)$.

Local control was significantly higher for peripheral lesions, compared to central lesions ( $\mathrm{p}=$ $0.025)$, resulting in 1-, 2-, and 3-year LC rates of $91 \%$ vs $74 \%$, $79 \%$ vs $63 \%$, and $60 \%$ vs $56 \%$, respectively (Figure 3).

In univariate Cox regression model, larger GTV and PTV volumes were associated with a higher risk of local relapse ( $p=0.0034$ and $p=0.0013$, respectively).

The variables tested in multivariate analysis were tumor type (primary/recurrent/metastasis), tracking (yes/no), confirmed histology (yes/no), location of lesions (central/peripheral), $\mathrm{BED}_{10 \mathrm{GG} \mathrm{y}^{\prime}} \mathrm{GTV}, \mathrm{PTV}$, and PTV coverage. These variables were selected in order to determine treatment and tumor factors influencing LC. In multivariate analysis the metastatic origin of lesions $(\mathrm{HR}=7.3 ; \mathrm{p}<0.0001)$, the histological confirmation of malignancy $(\mathrm{HR}=4.1 ; \mathrm{p}=$ 0.0052) and larger PTV (HR = 1.03; $\mathrm{p}<0.0001)$ were associated with significantly lower LC rate.

\section{Overall survival and cause-specific survival}

One-, two-, and three-year actuarial rates of OS were $85 \%, 74 \%$ and $62 \%$, respetively, whereas the respective rates of CSS were $93 \%, 90 \%$, and $80 \%$.

\section{Early and late toxicities}

Treatment related Grade $(\mathrm{G}) 3$ or higher acute and late toxicities were observed at $3(2 \%)$ and 6 patients (5\%), respectively. Acute toxicities included 2 cases (1.5\%) of G3 pneumonitis and a single case $(0.8 \%)$ of 
TABLE 4. Comparative table of relevant published data and own results

\begin{tabular}{|c|c|c|c|c|c|c|c|c|}
\hline Study & Technic & $\begin{array}{l}\text { Histological } \\
\text { confirmation } \\
\%\end{array}$ & $\begin{array}{l}\text { No. of } \\
\text { pts/ } \\
\text { lesions }\end{array}$ & dose (Gy)/fx & $\mathrm{BED}_{10 G \mathrm{G}}$ (Gray) & $\begin{array}{l}\text { Median } \\
\text { FUP } \\
\text { (month) }\end{array}$ & Local Control & $\begin{array}{l}\text { Overall } \\
\text { Survival }\end{array}$ \\
\hline \multicolumn{9}{|l|}{ PRIMARY } \\
\hline $\begin{array}{l}\text { van der Voort } \\
\text { van Zyp (27) }\end{array}$ & CK & 51 & 70 & $\begin{array}{l}\text { 60/3fx (Peripheral) } \\
45 / 3 f x \text { (Central) }\end{array}$ & $\begin{array}{l}180 \text { (Peripheral) } \\
112.5 \text { (Central) }\end{array}$ & 15 & $\begin{array}{l}96 \% @ 2 y \text { for } 60 \mathrm{~Gy} \\
78 \% @ 2 y \text { for } 45 \mathrm{~Gy}\end{array}$ & $62 \% @ 2 y$ \\
\hline Factor (28) & CK & 95 & 78 & $\begin{array}{l}\text { 60/3 fx (Peripheral) } \\
48 / 4 \text { fx (Central) }\end{array}$ & $75-180$ & 14.4 & $87 \% @ 2 y$ & $68 \% @ 2 y$ \\
\hline Shen (29) & CK & 84 & 50 & $57(48-60) / 3 f x$ & $104-150$ & 35 & crude 96\%@2y & $\begin{array}{l}86 \% @ 1 y \\
74 \% @ 2 y\end{array}$ \\
\hline Davis, RSS REGISTRY (5) & $\begin{array}{l}\text { CK, } \\
\text { LINAC }\end{array}$ & 100 & $723 / 741$ & median $54(10-80) / 3 \mathrm{fx}$ & 151.2 & 12 & $\begin{array}{l}88 \% @ 1 y \\
76 \% @ 2 y\end{array}$ & $\begin{array}{l}\text { T1:85/63\%@1/2y } \\
\text { T2: 76/52@1y/2y }\end{array}$ \\
\hline Fakiris (30) & LINAC & 100 & 70 & $60-66 / 3 f x$ & $180-211.2$ & 50.2 & $88.1 \% @ 3 y$ & 42.7\%@3y \\
\hline \multicolumn{9}{|c|}{ MIXED: PRIMARY+METASTASES } \\
\hline Guckenberger (31) & LINAC & 19 & $124 / 159$ & $26 / 1 \mathrm{fx} ; 37.5 / 3 ; 48 / 8 \mathrm{fx}$ & & 14 & 83\%@3y & $\begin{array}{l}\text { 37\%@3y (Primary) } \\
\text { 16\%@3y (Met) }\end{array}$ \\
\hline Ernst-Stecken (9) & LINAC & 100 & $21 / 39$ & $35-40 / 5 \mathrm{fx}$ & $59.5-72$ & 6.3 & crude: $87 \%$ & crude: $86 \%$ \\
\hline Duncker-Rohr (32) & LINAC & 55 & $39 / 45$ & $37.5 / 3 \mathrm{fx} ; 30 / 5 \mathrm{fx}$ & $\begin{array}{l}84 \text { (Peripheral) } \\
60 \text { (Central) }\end{array}$ & 17 & $\begin{array}{l}\text { 80.5\%@2y } \\
95 \% \text { @2y Prim } \\
59.7 \% @ 2 y \text { Met }\end{array}$ & $\begin{array}{l}52.7 \% @ 2 y \\
45.9 \% \text { (Primary) } \\
66.7 \% \text { (Met) }\end{array}$ \\
\hline Current study & CK & $\begin{array}{l}\text { total } 61 \% \\
\text { primary } 77 \%\end{array}$ & $130 / 160$ & $\begin{array}{l}\text { median 60/3 fx (Peripheral) } \\
\text { median } 45 / 5 \text { fx (Central) }\end{array}$ & $\begin{array}{l}\text { median } 180 \text { (Peripheral) } \\
\text { median } 112.5 \text { (Central) }\end{array}$ & 21 & $\begin{array}{l}86 \% @ 1 y \\
75 \% @ 2 y \\
62 \% @ 3 y\end{array}$ & \\
\hline
\end{tabular}

$\mathrm{BED}=$ mean biologically equivalent dose $\mathrm{CK}=$ Cyberknife; $\mathrm{fx}=$ fractions; $\mathrm{LINAC}=$ linear accelerator, Met $=$ metastases; Prim $=$ primary tumour; $\mathrm{Y}=\mathrm{yea}$

G5 pulmonary haemorrhage. This latter elderly (85 years old) patient had a fatal ipsilateral pulmonary haemorrhage 1 month after the completion of his SBRT (45 Gy in 5 fractions) for a right sided central tumor recurrence, and was classified as a possible treatment related adverse event. The patient had already been treated with chemotherapy 4 years earlier for his primary lung tumor, and 1 year earlier by Cyberknife for a contralateral upper lobe relapse without progression until the time of death.

Late toxicities were G3 dyspnea $(\mathrm{n}=3 ; 2.3 \%$, all presenting with chronic obstructive pulmonary disease [COPD] Global Initiative for Chronic Obstructive Lung Disease [GOLD] III prior to SBRT), G3 sick sinus syndrome $(\mathrm{n}=1 ; 0.8 \%)$ requiring pacemaker implantation 8 months after SBRT, G3 pain due to a rib fracture requiring major analgesic $(\mathrm{n}=1 ; 0.8 \%)$. One patient $(0.8 \%)$ suffered a fatal haemorrhage (G5) 7 months after SBRT for a centrally located recurrent tumor mass, which invaded vascular structures already at the time of detection, and had shown progression after
Cyberknife treatment (40 Gy in 5 fracions). This case was encoded as a treatment related adverse event, although local tumor progression could not be formally excluded.

Grade 2 late toxicities were also recorded such as asymptomatic or moderately painful rib fractures $(\mathrm{n}=5 ; 3.8 \%)$, recurrent laryngeal nerve palsy $(\mathrm{n}=$ $1 ; 0.8 \%)$, late radiation pneumonitis $(n=14 ; 10.8 \%)$ and pneumothorax $(n=6 ; 4.6 \%)$ after transthoracic marker placement requiring tube placement for a few days.

\section{Discussion}

High ( $86 \%, 75 \%$, and $62 \%$ at 1,2 , and 3 years) actuarial LC rates were observed at the first 130 consecutive patients treated with lung SBRT in our institution. Our results are comparable with published data from other lung SBRT series (Table 4). ${ }^{4-5,7-9,}, 22-28$ Bahig et al. reported their results on 150 patients treated with Cyberknife with a median dose of 60 
Gy in 3 fractions leading to exellent LC rates of $96 \%$ at 2 years. This cohort, including peripheral and central tumors, consisted of purely stage T1-2 primary NSCLC. ${ }^{4}$ In our study favorable LC was observed for primary tumors compared to metastatic lesions. The same finding was reported by Duncken-Rohr ${ }^{32}$, while Guckenberger et al. ${ }^{31} \mathrm{n}=$ 41; Stage IA, $\mathrm{n}=13$; Stage IB, $\mathrm{n}=19$; T3N0, $\mathrm{n}=9$ showed comparable 3-year results for primary and metastatic lesions treated with SBRT between the two groups at 3 years. In a comparative study of primary and metastatic lung tumors by Yamamoto et al. ${ }^{33}$ tumor diameter and metastatic origin were associated with significantly lower LC rates, which is congruent with our findings.

Location of the target in lung SBRT has an important role in defining maximum deliverable doses in function of their proximity to adjacent radiosensitive OARS. In our analysis, LC rates at 1-, 2-, and 3-years are significantly different between central and peripheral lesions. The same observation was reported by van der Voort van Zyp et al. with LC of $96 \%$ vs.78\% LC at 2 years for peripheral vs. central T1-2 NSCLC lung tumors treated with 60 Gy or 45 Gy in 3 fractions, respectively. ${ }^{27}$

The question of optimal dose of SBRT for central lesions remains unclear however, careful and appropriate dose-fractionation can lead to high tumor control with low rate of severe toxicities even in this population. In our series the overall mean $\mathrm{BED}_{10 \mathrm{~Gy}}$ was $151 \mathrm{~Gy}$ with a range between 72-180 Gy. As the total dose and the number of fractions was determined by the location and the size of the target lesion, the same treatment schedules were applied for primary, recurrent and metastatic lesions. Central lesions were treated with a mean / median $\mathrm{BED}_{10 \mathrm{~Gy}}$ of 102/112.5 Gy, the corresponding doses for peripheral lesions were 170/180 Gy, respectively. Obviously, the above seen better local control rates for peripheral tumors were linked to higher deliverable dose.

In a recent systematic review of central tumors Senthi et al. ${ }^{34}$ have found that LC rates $\geq 85 \%$ can be achieved with low rates of complications when prescribed BED on the tumor is $\geq 100 \mathrm{~Gy}$, and at the same time the biologically equivalent normal tissue dose does not exceed $210 \mathrm{~Gy}$. In a recent multicentric analysis of linac based central lung SBRT for NSCLC in German and Austrian institutions, the authors show similar LC rates to ours with $76 \%$, $64 \%$ and $52 \%$ at 1,2 , and 3 years with a delivered median $\mathrm{BED}_{10}$ of $72 \mathrm{~Gy}$ (range 43-180 Gy). ${ }^{35}$

In series reporting results of purely peripheral, T1-2 NSCLC treated with similar technology and doses to ours, LC rates as high as $83.8-100 \%$ were achieved at 2 years. ${ }^{26,29,36-38}$

A subgroup analysis of primary lung cancer patients in our cohort yielded actuarial 1-, 2-, and 3-year LC of $89 \%, 80 \%$, and $64 \%$, respectively. These results are similar to the findings of a recent, large scale publication on data of the RSSearch ${ }^{\circledR}$ Patient Registry of Radiosurgery Society reporting the clinical outcome of 723 patients with early stage, node negative NSCLC treated with various SBRT techniques achieving $88 \%$ and $76 \%$ LC rates at 1 and 2 years, respectively. ${ }^{5}$

For metastatic and recurrent patient groups we observed 1-, 2-, and 3-year LC rates of $84 \%, 59 \%$, $53 \%$ and $83 \%, 83 \%, 83 \%$, respectively. Inoue et al. ${ }^{8}$ reported comparable results (3-year LC rate of $80 \%$ ) in a large cohort study of central and peripheral metastases of 87 pts (189 lesions).

Although the distribition of patient numbers at the different dose-levels was particularly inbalanced in our cohort, analysis was performed on effect of $\mathrm{BED}_{10 \mathrm{~Gy}}$ on LC. A clear correlation between the applied dose and the actuarial local control rates were found with a cut-off at $\mathrm{BED}_{10 \mathrm{~Gy}}$ of 112.5 Gy, where lower doses were associated with higher rates of local recurrence. Local control rates at 1 , 2 , and 3 years were $93 \%$ vs $73 \%, 80 \%$ vs $61 \%$, and $63 \%$ vs $54 \%$, for the higher and lower dose groups, respectively ( $\mathrm{p}=0.0061, \mathrm{HR}=0.384$ ). These results are coherent with the findings of others, however dose cut-off was found to be somewhat lower in the literature. Onishi et al..$^{12}$ and Olsen et al. ${ }^{39}$ has shown that SBRT with a BED 10Gy $_{2} 100$ Gy was associated with significantly better LC rates than those with lower doses. In a large cohort study of 505 patients treated for NSCLC BED 10Gy $_{10} 105$ Gy predicted higher local recurrence rates of $15 \%$ vs $4 \%$ in the low dose and high dose group, respectively. ${ }^{40}$ In contrast, in a cohort of 94 NSCLC Stephans et al. ${ }^{41}$ did not observe a significant difference in 12 months actuarial LC between fractionation schemes of 5x10 Gy vs 3x20 Gy $\left(B^{2} D_{10 G y}=100\right.$ Gy vs 180Gy).

The limitations of our findings concerning the optimal $\mathrm{BED}_{10 \mathrm{~Gy}}$ include the inbalanced distribution of patients in different dose-level groups, the possible selection bias and the non-randomized nature of this cohort study.

The incidence of G3 or higher toxities in our study was coherent with the literature with $2 \%$ of acute and $5 \%$ of late complications. ${ }^{8,38}$ Two patients out of $130(1.5 \%)$ has died because of pulmonary haemorrhage. Grade 5 toxicities are rare, but existing complications of SBRT, occuring predominant- 
ly in centrally located tumors with an incidence of $0-2 \%$ in the literature. ${ }^{4,35}$ This low incidence of treatment realted deaths can reasonably be considered as acceptable, given the lack of treatment alternatives for this population.

\section{Conclusions}

Stereotactic ablative radiotherapy using the CybeKnife system for the treatment of primary, recurrent and metastatic lung lesions seems to be a safe and effective treatment option for medically inoperable patients. A clear dose-response relationship was confirmed with a significantly improved local control with $\mathrm{BED}_{10 \mathrm{~Gy}}$ over $112.5 \mathrm{~Gy}$. More firm data from prospective trials are needed to validate findings of this study.

\section{References}

1. van der Voort van Zyp NC, van der Holt B, van Klaveren RJ, Pattynama P, Maat A, Nuyttens JJ. Stereotactic body radiotherapy using real-time tumor tracking in octogenarians with non-small cell lung cancer. Lung Cancer 2010; 69: 296-301. doi: 10.1016/j.lungcan.2009.12.008

2. Chang JY, Senan S, Paul MA, Mehran RJ, Louie A V, Groen HJM, et al. Stereotactic ablative radiotherapy versus lobectomy for operable stage I non-small-cell lung cancer: a pooled analysis of two randomised trials. Lancet Oncol 2016; 16: 630-7. doi: 10.1016/S1470-2045(15)70168-3

3. Videtic GMM, Stephans K, Reddy C, Gajdos S, Kolar M, Clouser E, et al. Intensity-modulated radiotherapy-based stereotactic body radiotherapy for medically inoperable early-stage lung cancer: excellent local control. Int J Radiat Oncol Biol Phys 2010; 77: 344-9. doi: 10.1016/j.jirobp.2009.05.004

4. Bahig H, Filion E, Vu T, Roberge D, Lambert L, Bouchard M, et al. Excellent cancer outcomes following patient-adapted robotic lung SBRT but a case for caution in idiopathic pulmonary fibrosis. Technol Cancer Res Treat 2015; 14: 667-76. doi: $10.7785 /$ tcrt.2012.500445

5. Davis JN, Medbery C, Sharma S, Perry D, Pablo J, D’Ambrosio DJ, et al. Stereotactic body radiotherapy for early-stage non-small cell lung cancer: clinical outcomes from a National Patient Registry. J Radiat Oncol 2015; 4: 55-63. doi: 10.1007/s13566-014-0177-0

6. Baumann P, Nyman J, Hoyer M, Wennberg B, Gagliardi G, Lax I, et al. Outcome in a prospective phase II trial of medically inoperable stage I nonsmall-cell lung cancer patients treated with stereotactic body radiotherapy. J Clin Oncol 2009; 27: 3290-6. doi: 10.1200/JCO.2008.21.5681

7. Nuyttens JJ, van der Voort van Zyp NC, Verhoef C, Maat A, van Klaveren RJ, van der Holt B, et al. Stereotactic body radiation therapy for oligometastases to the lung: a Phase 2 Study. Int J Radiat Oncol Biol Phys 2015; 91: 337-43. doi: 10.1016/j.ijrobp.2014.10.021

8. Inoue $\mathrm{T}$, Oh $\mathrm{R}-\mathrm{J}$, Shiomi $\mathrm{H}$, Masai $\mathrm{N}$, Miura $\mathrm{H}$. Stereotactic body radiotherapy for pulmonary metastases. Prognostic factors and adverse respiratory events. Strahlenther Onkol 2013; 189: 285-92. doi: 10.1007/s00066-0120290-1

9. Ernst-Stecken A, Lambrecht U, Mueller R, Sauer R, Grabenbauer G. Hypofractionated stereotactic radiotherapy for primary and secondary intrapulmonary tumors: First results of a phase I/II study. Strahlenther Onkol 2006; 182: 696-702. doi: 10.1007/s00066-006-1577-x

10. De Ruysscher D, Faivre-Finn C, Nestle U, Hurkmans CW, Le Péchoux C, Price $A$, et al. European Organisation for Research and Treatment of Cancer recommendations for planning and delivery of high-dose, high-precision radiotherapy for lung cancer. J Clin Oncol 2010; 28: 5301-10. doi: 10.1200/ JCO.2010.30.3271
11. Vansteenkiste J, De Ruysscher D, Eberhardt WEE, Lim E, Senan S, Felip E, et al. Early and locally advanced non-small-cell lung cancer (NSCLC): ESMO Clinical Practice Guidelines for diagnosis, treatment and follow-up. Ann Oncol 2013; 24(Suppl 6): vi89-98. doi: 10.1093/annonc/mdt241

12. Onishi $H$, Shirato $H$, Nagata $Y$, Hiraoka $M$, Fujino $M$, Gomi $K$, et al. Hypofractionated stereotactic radiotherapy (HypoFXSRT) for stage I nonsmall cell lung cancer: updated results of 257 patients in a Japanese multi-institutional study. J Thorac Oncol 2007; 2(7 Suppl 3): S94-100. doi: 10.1097/JTO.0b013e318074de34

13. Hof $\mathrm{H}$, Herfarth KK, Münter M, Hoess A, Motsch J, Wannenmacher M, et al. Stereotactic single-dose radiotherapy of stage I non-small-cell lung cancer (NSCLC). Int J Radiat Oncol Biol Phys 2003; 56: 335-41. doi: 10.1016/S03603016(02)04504-2

14. Hof $\mathrm{H}$, Hoess A, Oetzel D, Debus J, Herfarth $\mathrm{K}$. Stereotactic single-dose radiotherapy of lung metastases. Strahlenther Onkol 2007; 183: 673-8. doi: 10.1007/s00066-007-1724-z

15. Senan S, Lagerwaard F. Stereotactic radiotherapy for stage I lung cancer: current results and new developments. Cancer Radiother 2010; 14: 115-8. doi: 10.1016/j.canrad.2009.11.003

16. Chen Y, Guo W, Lu Y, Zou B. Dose-individualized stereotactic body radiotherapy for T1-3NO non-small cell lung cancer: Long-term results and efficacy of adjuvant chemotherapy. Radiother Oncol 2008; 88: 351-8. doi: 10.1016/j. radonc.2008.07.013

17. Berriochoa C, Videtic GMM, Woody NM, Djemil T, Zhuang T, Stephans KL. Stereotactic body radiotherapy for T3NO lung cancer with chest wall invasion. Clin Lung Cancer 2016; 17: 595-601. doi: 10.1016/j.cllc.2016.04.007

18. Jereczek-Fossa BA, Ronchi S, Orecchia R. Is stereotactic body radiotherapy (SBRT) in lymph node oligometastatic patients feasible and effective? Rep Pract Oncol Radiother 2015; 20: 472-83. doi: 10.1016/j.rpor.2014.10.004

19. Meng M, Wang H, Zaorsky NG, Zhao X, Wu Q, Jiang B, et al. Clinical evaluation of stereotactic radiation therapy for recurrent or second primary mediastinal lymph node metastases originating from non-small cell lung cancer. Oncotarget 2015; 6: 15690-703. doi: 10.18632/oncotarget.3704

20. Gibbs IC. Frameless image-guided intracranial and extracranial radiosurgery using the Cyberknife robotic system. Cancer Radiother 2006; 10: 283-7. doi: 10.1016/j.canrad.2006.05.013

21. Kilby W, Dooley JR, Kuduvalli G, Sayeh S, Maurer CR. The CyberKnife robotic radiosurgery system in 2010. Technol Cancer Res Treat 2010; 9: 433-52. doi: $10.1177 / 153303461000900502$

22. Timmerman RD. An overview of hypofractionation and introduction to this issue of Seminars in Radiation Oncology. Semin Radiat Oncol 2008; 18: 215 22. doi: 10.1016/j.semradonc.2008.04.001

23. Benedict SH, Yenice KM, Followill D, Galvin JM, Hinson W, Kavanagh B, et al. Stereotactic body radiation therapy: the report of AAPM Task Group 101. Med Phys 2010; 37: 4078-101. doi: 10.1118/1.3438081

24. Guckenberger M, Heilman K, Wulf J, Mueller G, Beckmann G, Flentje M. Pulmonary injury and tumor response after stereotactic body radiotherapy (SBRT): results of a serial follow-up CT study. Radiother Oncol 2007; 85: 43542. doi: 10.1016/j.radonc.2007.10.044

25. Essler M, Wantke J, Mayer B, Scheidhauer K, Bundschuh RA, Haller B, et al. Positron-emission tomography $\mathrm{CT}$ to identify local recurrence in stage I lung cancer patients 1 year after stereotactic body radiation therapy. Strahlenther Onkol 2013; 189: 495-501. doi: 10.1007/s00066-013-0310-9

26. Chen VJ, Oermann E, Vahdat S, Rabin J, Suy S, Yu X, et al. CyberKnife with tumor tracking: an effective treatment for high-risk surgical patients with stage I non-small cell lung cancer. Front Oncol 2012; 2: 1-5. doi: 10.3389/ fonc.2012.00009

27. van der Voort van Zyp NC, Prévost J-B, Hoogeman MS, Praag J, van der Holt $B$, Levendag PC, et al. Stereotactic radiotherapy with real-time tumor tracking for non-small cell lung cancer: clinical outcome. Radiother Oncol 2009; 91: 296-300. doi: 10.1016/j.radonc.2009.02.011

28. Factor OB, Vu CC, Schneider JG, Witten MR, Schubach SL, Gittleman AE, et al. Stereotactic body radiation therapy for stage I non-small cell lung cancer: a small academic hospital experience. Front Oncol 2014; 4: 1-5. doi: 10.3389/fonc. 2014.00287

29. Shen Z-T, Wu X-H, Li B, Zhu X-X. Clinical outcomes of CyberKnife stereotactic body radiotherapy for peripheral stage I non-small cell lung cancer. Med Oncol 2015; 32: 1-8. doi: 10.1007/s12032-015-0506-1 
30. Fakiris AJ, McGarry RC, Yiannoutsos CT, Papiez L, Williams M, Henderson M A, et al. Stereotactic body radiation therapy for early-stage non-small-cell lung carcinoma: four-year results of a prospective phase II Study. Int J Radiat Oncol Biol Phys 2009; 75: 677-82. doi: 10.1016/j.jjrobp.2008.11.042

31. Guckenberger M, Wulf J, Mueller G, Krieger T, Baier K, Gabor M, et al. Doseresponse relationship for image-guided stereotactic body radiotherapy of pulmonary tumors: relevance of $4 \mathrm{D}$ dose calculation. Int J Radiat Oncol Biol Phys 2009; 74: 47-54. doi: 10.1016/j.jijrobp.2008.06.1939

32. Duncker-Rohr V, Nestle U, Momm F, Prokic V, Heinemann F, Mix M, et al Stereotactic ablative radiotherapy for small lung tumors with a moderate dose: Favorable results and low toxicity. Strahlenther Onkol 2013; 189: 3340. doi: 10.1007/s00066-012-0224-y

33. Yamamoto $T$, Jingu $K$, Shirata $Y$, Koto $M$, Matsushita $H$, Sugawara $T$, et al Outcomes after stereotactic body radiotherapy for lung tumors, with emphasis on comparison of primary lung cancer and metastatic lung tumors. BMC Cancer 2014; 14: 464. doi: 10.1186/1471-2407-14-464

34. Senthi S, Haasbeek CJ a, Slotman BJ, Senan S. Outcomes of stereotactic ablative radiotherapy for central lung tumours: A systematic review. Radiother Oncol 2013; 106: 276-82. doi: 10.1016/j.radonc.2013.01.004

35. Schanne DH, Nestle U, Allgäuer M, Andratschke N, Appold S, Dieckmann U, et al. Stereotactic body radiotherapy for centrally located stage I NSCLC: a multicenter analysis. Strahlenther Onkol 2014; 191: 125-32. doi: 10.1007/ s00066-014-0739-5

36. Brown WT, Wu X, Fayad F, Fowler JF, García S, Monterroso MI, et al. Application of robotic stereotactic radiotherapy to peripheral stage I nonsmall cell lung cancer with curative intent. Clin Oncol 2009; 21: 623-31. doi: 10.1016/j.clon.2009.06.006

37. Collins BT, Vahdat S, Erickson K, Collins SP, Suy S, Yu X, et al. Radical cyberknife radiosurgery with tumor tracking: an effective treatment for inoperable small peripheral stage I non-small cell lung cancer. J Hematol Oncol 2009; 2: 1. doi: 10.1186/1756-8722-2-1

38. Vahdat S, Oermann EK, Collins SP, Yu X, Abedalthagafi M, Debrito $\mathrm{P}$, et al. CyberKnife radiosurgery for inoperable stage IA non-small cell lung cancer: $18 \mathrm{~F}$-fluorodeoxyglucose positron emission tomography/computed tomography serial tumor response assessment. J Hematol Oncol 2010; 3: 6. doi: $10.1186 / 1756-8722-3-6$

39. Olsen JR, Robinson CG, El Naqa I, Creach KM, Drzymala RE, Bloch C, et al. Dose-response for stereotactic body radiotherapy in early-stage nonsmall-cell lung cancer. Int J Radiat Oncol Biol Phys 2011; 81: 299-303. doi: 10.1016/j.jijrobp.2011.01.038

40. Grills IS, Hope AJ, Guckenberger M, Kestin LL, Werner-Wasik M, Yan D, et al. A collaborative analysis of stereotactic lung radiotherapy outcomes for early-stage non-small-cell lung cancer using daily online cone-beam computed tomography image-guided radiotherapy. J Thorac Oncol 2012; 7: 1382-93. doi: 10.1097/JTO.0b013e318260e00d

41. Stephans KL, Djemil T, Reddy CA, Gajdos SM, Kolar M, Mason D, et al. A comparison of two stereotactic body radiation fractionation schedules for medically inoperable stage I non-small cell lung cancer: the Cleveland Clinic experience. J Thorac Oncol 2009; 4: 976-82. doi: 10.1097/ JTO.0b013e3181adf509 